\title{
Alkyl polyglycoside: a green and efficient surfactant for enhancing heavy oil recovery at high-temperature and high-salinity condition
}

\author{
Gang $\mathrm{Li}^{1} \cdot$ Lifeng Chen ${ }^{1} \cdot$ Yang Ruan ${ }^{1} \cdot$ Qiao Guo $^{1} \cdot$ Xingao Liao $^{1} \cdot$ Bowen Zhang ${ }^{1}$
}

Received: 22 February 2019 / Accepted: 8 April 2019 / Published online: 17 April 2019

(c) The Author(s) 2019

\begin{abstract}
Alkyl polyglycoside (APG) is a green surfactant with excellent interfacial activity, emulsified ability, foaming performance and wettability, which has great potential in enhancing heavy oil recovery at high-temperature and high-salinity condition. In this paper, surface tension, interfacial tension, emulsifying ability, emulsion stability and emulsified oil droplet size were investigated for APG. Besides, the effect of temperature and salinity on interfacial activity and emulsification properties of APG was also studied. The results showed that APG had excellent interfacial activity and emulsification property among all these surfactants. Besides, the interfacial activity and emulsification properties of APG almost did not decrease, and even got better along with the increasing temperature or salinity, while those of other surfactants became worse in different degree. The incremental oil recovery by using APG at $90^{\circ} \mathrm{C}$ and the salinity of $30 \mathrm{~g} / \mathrm{L}$ can reach to $10.1 \%$ which is nearly two times higher than that of common EOR surfactants. These results indicated that APG is an efficient surfactant for enhancing heavy oil recovery at high-temperature and high-salinity condition.
\end{abstract}

Keywords Surfactant $\cdot$ Alkyl polyglycoside $\cdot$ Interfacial activity $\cdot$ Emulsification property $\cdot$ Oil recovery

\section{Introduction}

With the depletion of conventional oil reserve, the effective development of the massive amount of heavy oil becomes increasingly important. However, the high viscosity of heavy oil makes it difficult to recover. The most widely used EOR techniques being employed for recovering heavy oil are thermal methods, which are to improve oil mobility by reducing the viscosity of heavy oil (Bi et al. 1999). However, severe heat losses make the application of thermal methods for the deep or thin heavy oil reservoirs very unattractive (Salager et al. 1979). Thus, it is necessary to consider the non-thermal methods for the recovery of these oils.

Chemical flooding, such as surfactant flooding and surfactant/polymer flooding, is a common non-thermal technique for heavy oil (Norman 1990; Taylor and Schramm 1990; James 1980; Wasan et al. 1978). It is well known that the key problem in heavy oil reservoir is inefficient sweep due to low mobility of the oil, not the residual oil in the

Lifeng Chen

LYJ505523522@126.com

1 College of Petroleum Engineering, Yangtze University, Wuhan 430100, China swept region (Chiang and Shah 1979; Guo 2010; Sun et al. 2011). As a result, excellent emulsions caused by the good interfacial activity and emulsification properties of the surfactant play a prominent role to increase sweep efficiency to enhance viscous oil recovery. However, most surfactants, which have nice interfacial activity and emulsification properties at conventional reserve environment, cannot show the identical performance at high-temperature and high-salinity condition (Ding et al. 2010; McClean and Kilpatrick 1997; Gafonova and Yarranton 2001). Therefore, getting a thermalresistance and salt-tolerance surfactant is the key to enhancing the heavy oil recovery.

APG is a green surfactant obtained by the dehydration reaction between glucose hemiacetal hydroxyl and fatty alcohol hydroxyl in the presence of acid catalyst. Its raw materials are the vegetable oil and starch which are the natural renewable resource and low cost, and its biodegradability is very excellent. More importantly, the oil displacement performances of APG, such as emulsified ability, foaming performance, wettability, are all prominent (Payet and Terentjev 2008). Hence, APG has great potential in oilfield chemistry. As already pointed out, superior EOR surfactant systems must have good interfacial activity and can reduce the oil/water IFT to the ultra-low value. Balzer (Balzer 1991) 
measured the IFTs between water and three different model oils in the presence of APG surfactants. Kutschmann et al. (Kutschmann et al. 1995) and Kahlweit et al. (Kahlweit et al. 1995) determined the IFT in combination with linear alcohols as co-solvents. They all identified that the surfactant formulations could obtain an ultra-low IFT in brine/alkane or brine/xylene systems. Furthermore, researches (Iglauer et al. 2009; Monika et al. 2011; Chen et al. 2013; Jiang et al. 2008) also showed that the IFTs of these APG/alkali formulations could also reach an ultra-low value, while the emulsification properties were excellent. Therefore, promoting the application of APG is favorable for oil production to meet the need of the environmental protection and sustainable development.

However, the previous research objects used to investigate oil displacing performance of APG are all simulated oil or light oil; the oil displacing capacity of APG on heavy oil nearly has not been studied. Therefore, the objective of this study is to assess the technical feasibility of APG for enhancing heavy oil recovery at high-temperature and high-salinity condition. In this paper, surface tension, interfacial tension, emulsifying ability, emulsion stability and emulsified oil droplet size were investigated for APG and other common EOR surfactants, and the effect of temperature and salinity on interfacial activity and emulsification properties of APG was also studied. Sandpack flooding tests were conducted to examine the effectiveness of APG on enhanced heavy oil recovery at high-temperature and high-salinity condition.

\section{Experimental procedures}

\section{Materials}

The heavy oil sample was collected from Shengli oilfield, and the basic properties are shown in Table 1. The eight surfactants were Shengli petroleum sulfonate (SLPS), heavy alkylbenzene sulfonate (HABS), $\alpha$-olefin sulfonate (AOS), sodium dodecyl benzene sulfonate (ABS), alkyl polyglucosides (APG), octylphenol ethoxylates (OP-10), dodecyl betaine (BS-12) and fatty alcohol polyoxyethylene ether sulfate (AES), and they were purchased from Sinopharm or Shengli Oil Field. It should be noted that the chemicals concentration in the paper is an effective content and on a weight basis.

Table 1 Properties of Heavy Oil Used

\begin{tabular}{lllll}
\hline $\begin{array}{l}\text { Density } \\
\left(\mathrm{g} \mathrm{cm}^{-3},\right.\end{array}$ & $\begin{array}{l}\text { Viscosity } \\
(\mathrm{mPa} \mathrm{s}, \\
\left.50{ }^{\circ} \mathrm{C}\right)\end{array}$ & $\begin{array}{l}\text { Acid value } \\
\left(\mathrm{mg} \mathrm{g}^{-1}\right)\end{array}$ & $\begin{array}{l}\text { Asphaltene } \\
\text { level }(\%)\end{array}$ & $\begin{array}{l}\text { Resin level } \\
(\%)\end{array}$ \\
\hline 0.933 & 586 & 1.08 & 1.09 & 18.56 \\
\hline
\end{tabular}

\section{Measurements}

In this paper, the experimental temperature was always $50{ }^{\circ} \mathrm{C}$ except the special instruction. Triplet tests were performed for each measurement, and the average of three readings was considered as the final in the whole experimental procedure.

\section{Determination of surface tension (SFT)}

SFT measurements for different surfactant solutions of different concentrations were obtained by using a SL.NO-163 tensiometer with Du-Nouy ring at $25^{\circ} \mathrm{C}$.

\section{Determination of interfacial tension (IFT)}

The oil-water IFT was determined by using the Texas-500 spinning drop tensiometer at different conditions.

\section{Determination of emulsifying ability}

The colorimetric method (Chen et al. 2013) was used to measure the emulsifying ability of surfactants in this paper, and its mechanism was as follows: the oil with color and the surfactant in a certain proportion are mixed fully, and the mixture is oscillated to produce emulsion after adding some water. The oil in the emulsion phase is extracted by organic solvent after the emulsion stratifies, and then the absorbance of the extract liquid is determined. The oil content is obtained according to the corresponding absorbance on the standard curve. Thus, the emulsifying ability is characterized by the ratio of emulsified oil weight accounting for the total weight of initial oil.

\section{Determination of emulsion stability}

Emulsion stability experiments were performed by using the bottle test. Surfactant solution and crude oil were mixed in a colorimetrical cylinder. This mixture was set and not shaken for $10 \mathrm{~min}$ in the thermostat water bath of $50{ }^{\circ} \mathrm{C}$. Then the mixture solution was vigorously shaken by hand, 100 times in $100 \mathrm{~s}$, as uniformly as possible, then kept at $50^{\circ} \mathrm{C}$ again, and the volume of the emulsion phase was noted at the given time.

\section{Determination of particle size distribution}

The oil droplet size of the emulsion prepared in the measurement process of emulsifying ability was determined by the GSL-101BII laser particle size analyzer. Meanwhile, the 
micro-morphology of emulsified drops was observed by the $\mathrm{XSP}-8 \mathrm{CE}$ biomicroscope, and the scale length in the figure is 10 microns.

\section{Core-flooding experiments}

The permeability and porosity of the vacuum-pumping core were measured firstly; then crude oil was injected into the wetpacked core until the core reached the connate water saturation. After aging for $24 \mathrm{~h}$, formation water (whose salinity was the same as that of surfactants slug used) was injected into the core until the water cut reached $98 \%$. Then $0.5 \mathrm{PV}$ (PV is the pore volume of the core) of surfactants slug was injected into the core following the previous water flooding. Finally, water was injected into the core persistently until the water cut reached $98 \%$ again. The volumetric flow rate of water phase and oil phase was 0.5 and $0.3 \mathrm{ml} / \mathrm{min}$, respectively. All the experiments were conducted at the temperature of $90^{\circ} \mathrm{C}$ and the salinity of $30,000 \mathrm{mg} / \mathrm{L}$.

\section{Results and discussions}

\section{Surface activity}

The SFT minimum $\left(\mathrm{SFT}_{\min }\right)$ and critical micelle concentration (CMC) are shown in Table 2. Obviously, APG has the best surface activity. It has the lowest $\mathrm{SFT}_{\text {min }}(27.9 \mathrm{mN} / \mathrm{m})$ which means the ability of decreasing the SFT and the minimum CMC $(0.008 \%)$ which represents the efficiency of decreasing the SFT; comparatively speaking, the CMC of the anionic surfactants (SLPS, HABS, AOS, ABS) is higher than that of nonionic ones (APG, OP-10) and zwitterionic ones (BS-12, $\mathrm{AES})$, and the $\mathrm{SFT}_{\text {min }}$ shows the similar rule. It indicates that the CMC of surfactants has a positive correlation with the $\mathrm{SFT}_{\min }$ to some extent.

\section{Interfacial activity}

\section{Effect of the surfactant concentration on IFT}

The oil-water IFT of different surfactants with the concentration range from 0.1 to $0.8 \%$ is shown in Fig. 1 . For almost the whole surfactants, the IFT reduces as the concentration rises. When the concentration is high, there are more surfactant molecules adsorbing at the oil-water interface, so the IFT is low. APG and OP-10 can decrease the IFT to $10^{-1} \mathrm{mN} / \mathrm{m}$ at a very low concentration, and increasing the concentration cannot

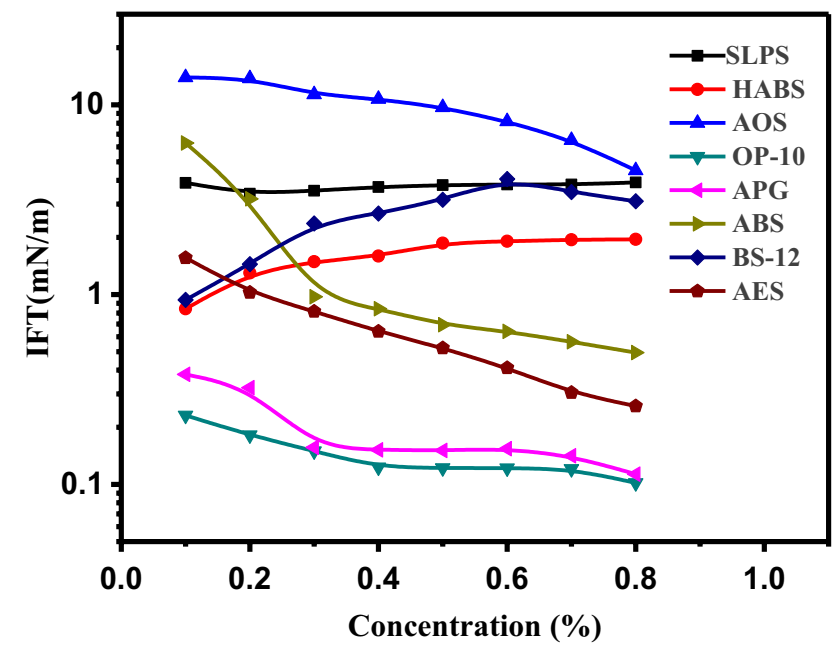

Fig. 1 Interface tension of different surfactants changing with the concentration

improve their interfacial activity remarkably. In other words, APG and OP-10 can get excellent interfacial activity with less dosage, so they are more applicable to improve the heavy oil recovery in Shengli Oil Field.

\section{Effect of temperature on IFT}

ABS, APG and BS-12 were selected as the representative for the anionic surfactant, nonionic one and zwitterionic one, respectively, to investigate the effect of temperature on IFT. As shown in Figs. 2, 3 and 4, the interfacial activity of ABS and BS-12 gets worse at high-temperature condition. On the contrary, the IFT between APG solution and oil reduces with the rising temperature. APG molecule is rigid due to containing the cyclic structure; then its thermostability is improved obviously, and it is not easy to be desorbed from the oil-water interface due to the increasing temperature. Moreover, since APG is a nonionic surfactant, its solubility in water decreases resulting from rising the temperature. So more surfactant molecules absorb onto the interface and the IFT attains a lower value. Therefore, APG can be suitable to enhance heavy oil recovery at high-temperature condition.

\section{Effect of inorganic salt on IFT}

Besides the surfactant concentration and temperature, inorganic salt is another influencing factor on the interfacial activity. The $\mathrm{NaCl}$ solution was used to study the
Table 2 Surface activity of surfactants

\begin{tabular}{|c|c|c|c|c|c|c|c|c|}
\hline Surfactant & SLPS & HABS & AOS & ABS & APG1214 & OP-10 & BS-12 & AES \\
\hline SFTmin, $\mathrm{mN} / \mathrm{m}$ & 33.2 & 33.2 & 38.7 & 37.4 & 27.9 & 34.7 & 30.2 & 33.3 \\
\hline CMC, \% & 0.1 & 0.05 & 0.2 & 0.3 & 0.008 & 0.05 & 0.08 & 0.06 \\
\hline
\end{tabular}




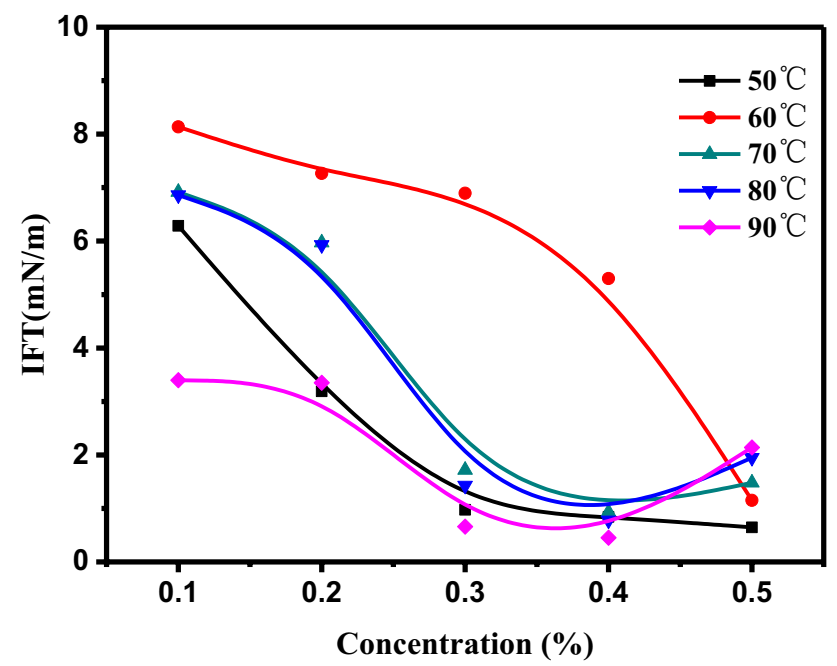

Fig. 2 Effect of temperature on IFT of ABS

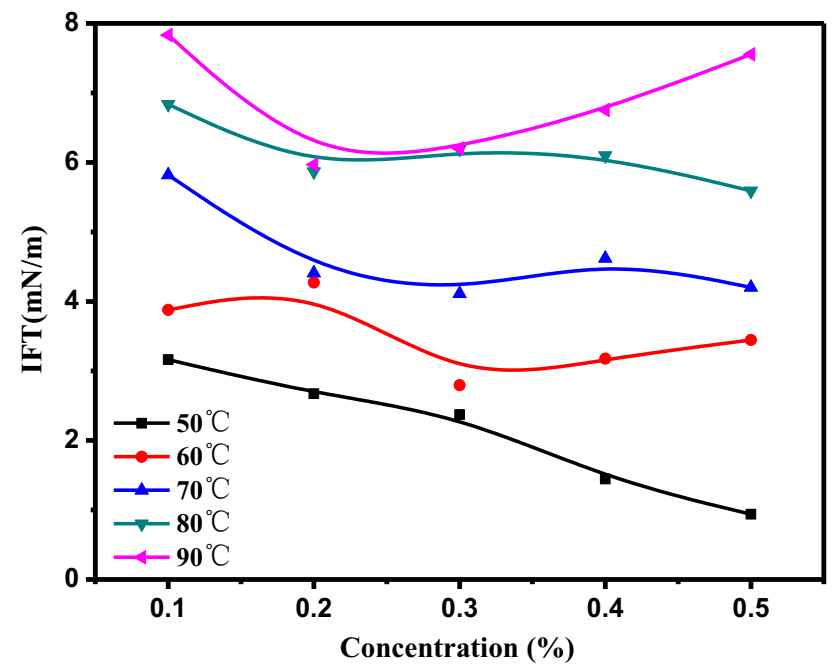

Fig. 3 Effect of temperature on IFT of BS-12

effect of inorganic salt on IFT, and the result is shown in Fig. 5. The oil-water IFT of ABS reduces by increasing the concentration of $\mathrm{NaCl}$ solution while that of BS-12 increases first and then decreases. In contrast, the IFT between APG solution and oil keeps almost constant by changing the concentration of $\mathrm{NaCl}$ solution. Hence, for each surfactant, the proper concentration of inorganic salt is beneficial to enhance its interfacial activity. The inorganic salt ions can affect significantly on the ionic surfactant due to the electrostatic interaction, and then the IFT is influenced. APG is the nonionic surfactant, so its interfacial activity is nearly not affected by the inorganic salt. Therefore, APG is more adaptive to the heavy oil reservoir with a large range of salinity.

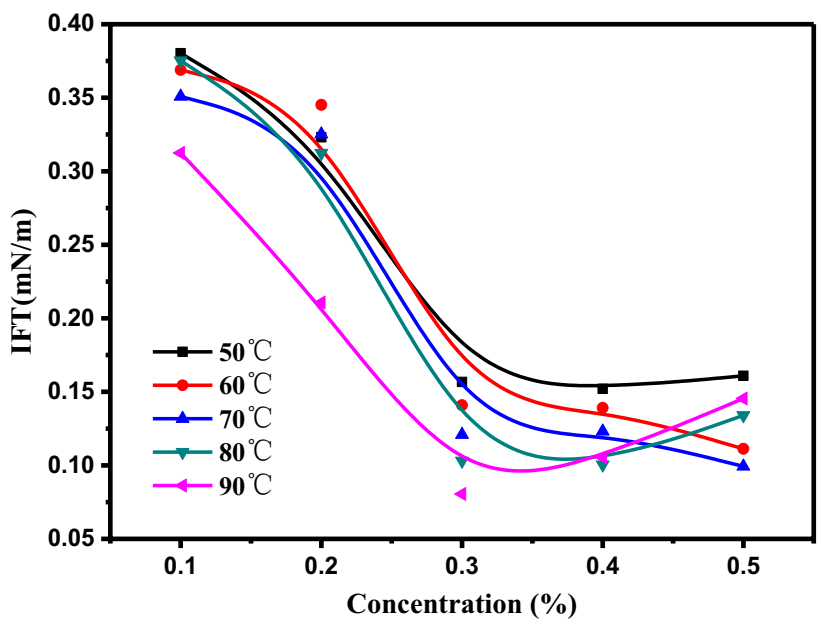

Fig. 4 Effect of temperature on IFT of APG

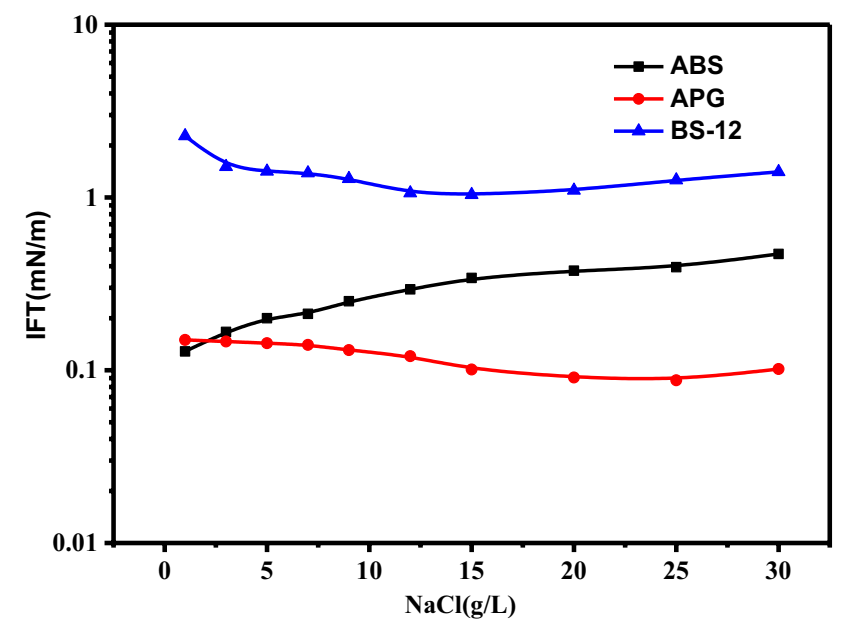

Fig. 5 Effect of $\mathrm{NaCl}$ on IFT of different surfactants

\section{Emulsifying ability}

\section{Effect of temperature on emulsifying ability}

The emulsifying ability of surfactants at different temperature conditions is shown in Fig. 6. It is influenced significantly by temperature, and the changing trends of emulsifying ability are different from each other. In general, increasing the temperature appropriately is conducive to enhance the emulsifying ability, but too high temperature usually reduces it. There is an optimum temperature for every surfactant at which the emulsifying ability is the best. So according to the best applicable temperature for emulsifying, the surfactant can be selected as the emulsifier better to be applied to the oil reservoir with different temperature conditions. Obviously, the emulsifying ability 


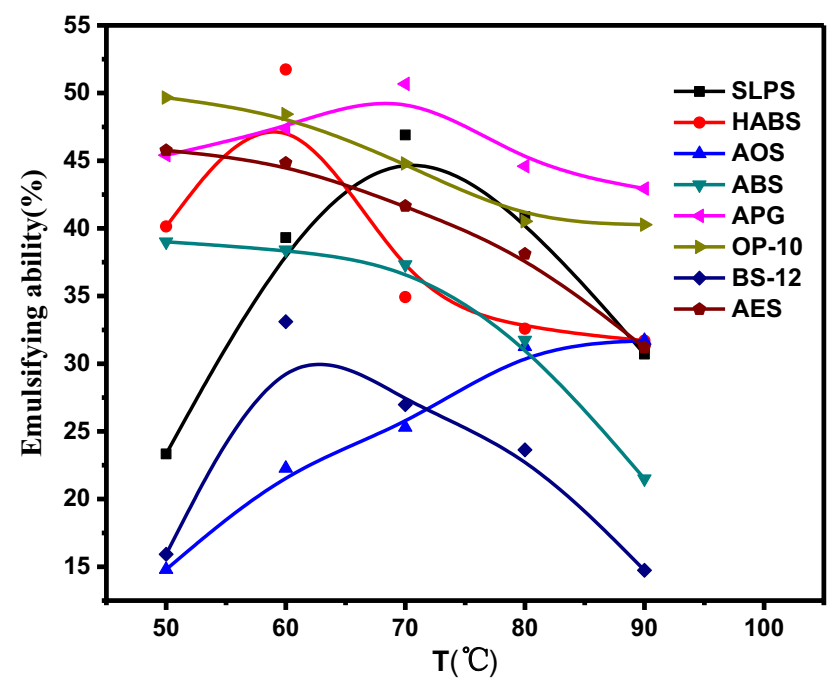

Fig. 6 Effect of temperature on emulsifying ability of different surfactants

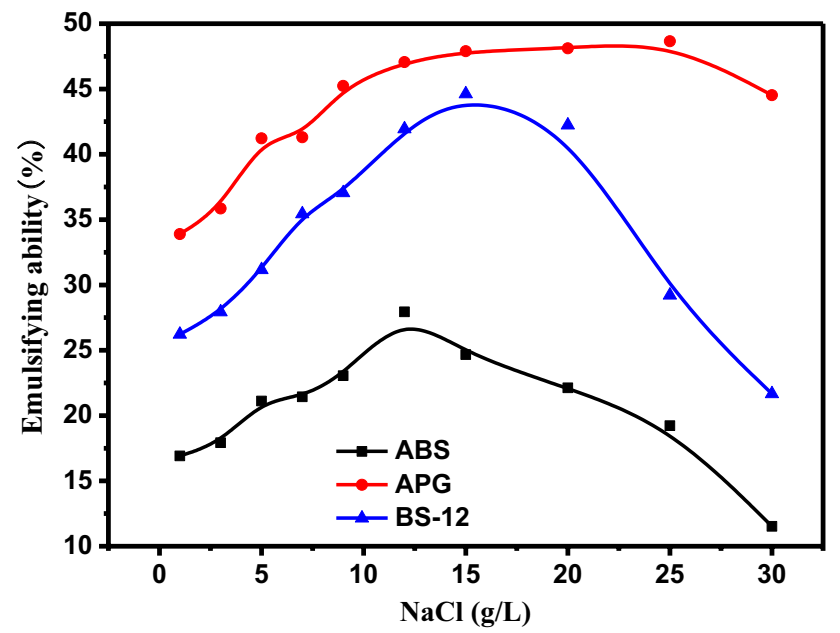

Fig. 7 Effect of $\mathrm{NaCl}$ on emulsifying ability of different surfactants

of APG is the strongest, which indicates APG can form emulsion with oil easily.

\section{Effect of inorganic salt on emulsifying ability}

The formation water contains inorganic salt which affects the emulsifying ability, so investigating the effect of inorganic salt on emulsifying ability is necessary. Figure 7 shows the changes of emulsifying ability resulting from the variation of the inorganic salt concentration. With the increasing salinity, the emulsifying ability of three surfactants increases first and then decreases, and attains the peak at a certain concentration. The emulsifying ability of APG is always more excellent than that of ABS and BS-12, especially at the high concentration of $\mathrm{NaCl}$. After the concentration of $\mathrm{NaCl}$ solution reaches $9 \mathrm{~g} / \mathrm{L}$, the emulsifying ability of APG only changes a little with the increasing concentration. Therefore, as the emulsifier, APG is much more suited for the increasing highsalinity reservoirs.

\section{Emulsion stability}

\section{Effect of the surfactant concentration and time on emulsion stability}

The oil-water separation in emulsion makes the volume of emulsion phase reduce. Obviously, the more the volume of residual emulsion phase is, the steadier the emulsion is. As shown in Fig. 8, the volume of emulsion phase universally increases with the increasing surfactant concentration. Because the interfacial film is the determinant factor for the emulsion stability, its strength is enhanced when more surfactant molecules form the oil-water interfacial film. In another word, higher concentration surfactant results in steadier emulsion. The effect of time on emulsion stability is shown in Fig. 9. The emulsion whose stability is bad demulsifies very quickly, and there is left only a little emulsion phase after $10 \mathrm{~min}$. On the contrary, the emulsion which has better stability needs at least $30 \mathrm{~min}$ for the demulsification and then nearly remains steady. Combined with Figs. 8 and 9, APG possesses the best emulsion stability, and it can be used as emulsifying stabilizer for heavy oil preferably.

\section{Effect of temperature on emulsion stability}

The formation temperature influences the emulsion stability which is related with improving the oil displacement efficiency, so investigating the effect of temperature on emulsion stability is essential. As shown in Figs. 10, 11

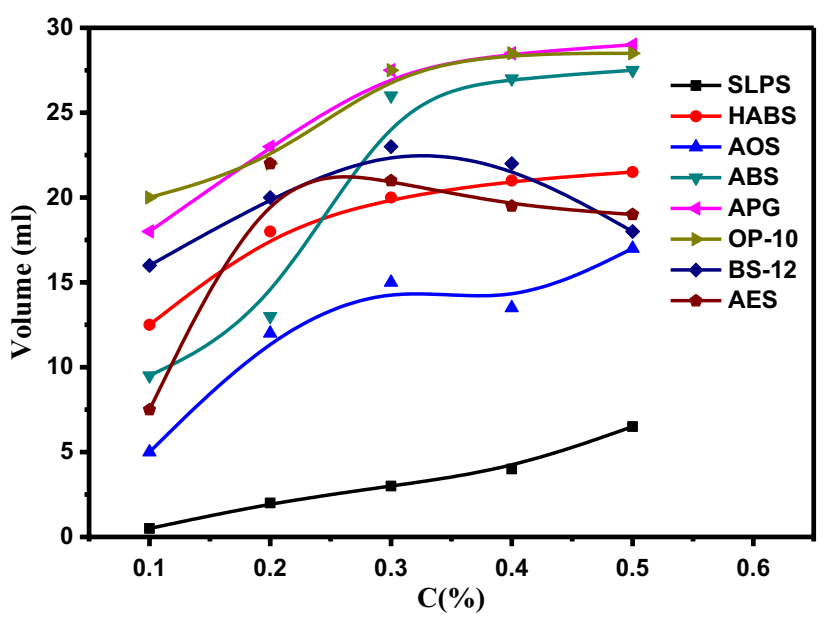

Fig. 8 Volume of emulsion phase versus surfactant concentration at 5th min 


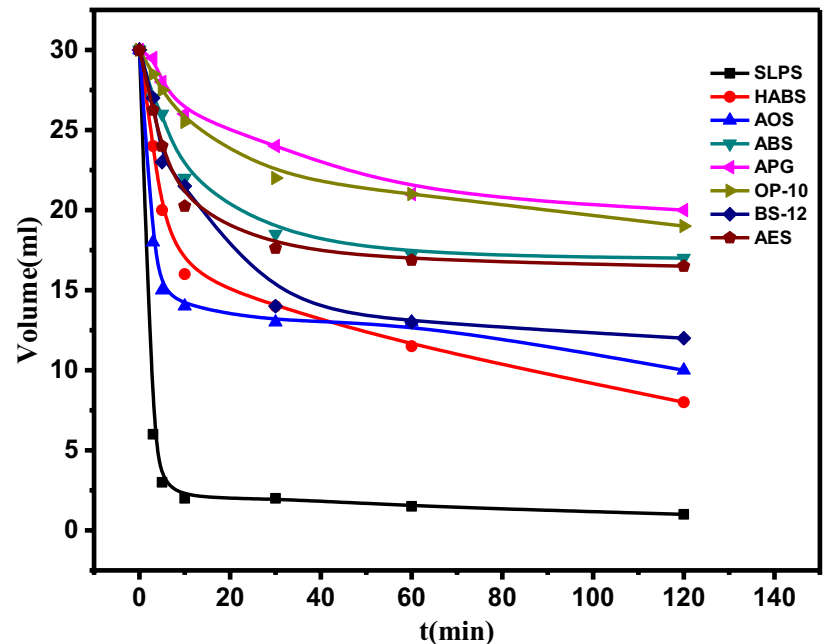

Fig. 9 Volume of emulsion phase at different times

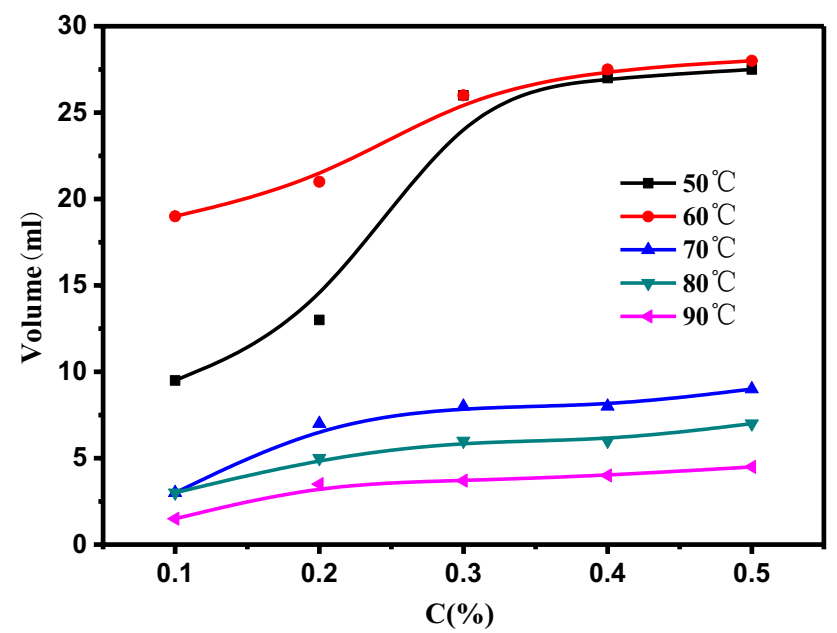

Fig. 10 Volume of emulsion phase versus the concentration of ABS at 5 th $\min$

and 12 , rising temperature decreases the emulsion stability of ABS and BS-12, but the emulsion stability of APG basically gets better with the increasing temperature. The emulsification ratio (the ratio between the volume of emulsion phase and the total volume of emulsion system) of APG can still remain about $90 \%$ when the temperature even reaches to $90{ }^{\circ} \mathrm{C}$. Heavy oil production usually needs extra heat from the ground to reduce the viscosity, and then the production temperature of heavy oil reservoirs is usually higher than that of common ones. So APG can better meet the need of enhancing heavy oil recovery.

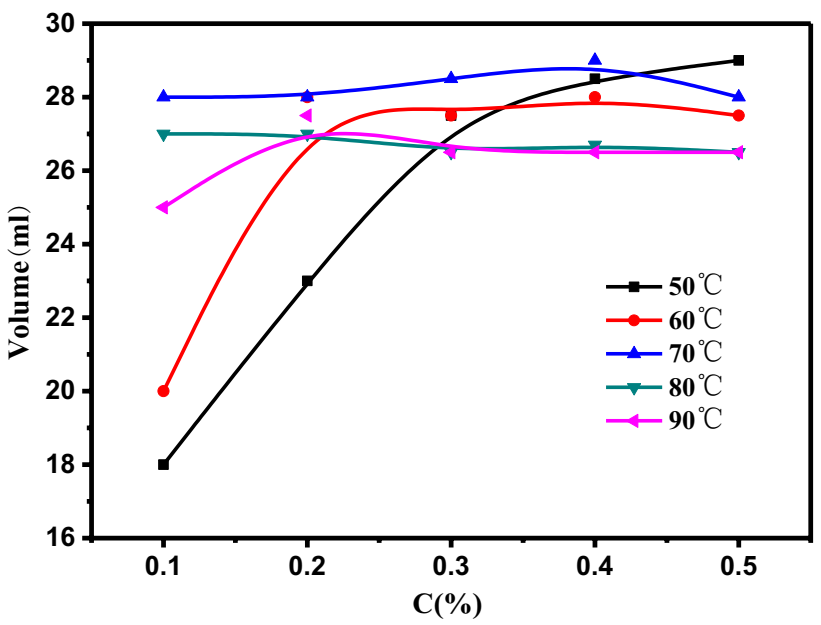

Fig. 11 Volume of emulsion phase versus the concentration of APG at 5 th $\min$

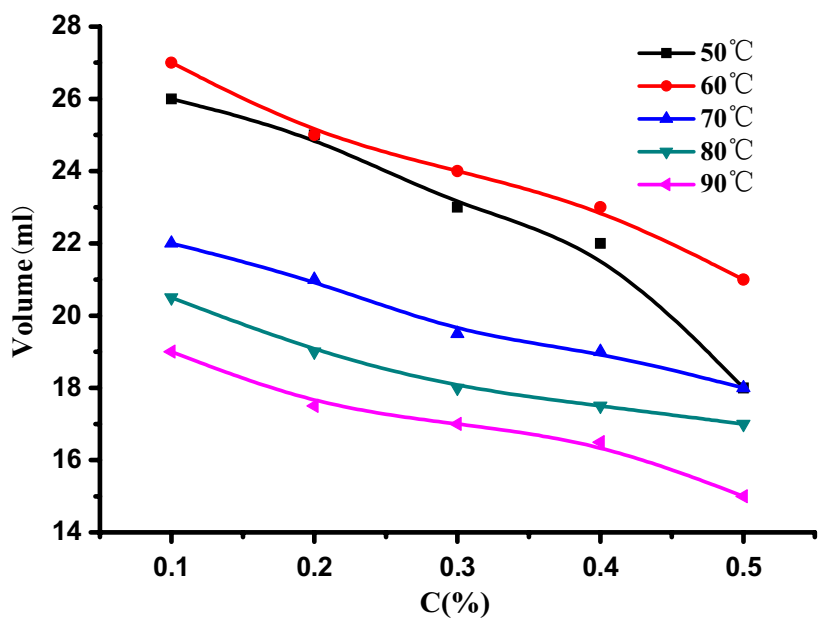

Fig. 12 Volume of emulsion phase versus the concentration of BS-12 at 5 th $\min$

\section{Effect of inorganic salt on emulsion stability}

The effect of inorganic salt on emulsion stability is shown in Fig. 13. The emulsion stability of ABS is affected by $\mathrm{NaCl}$ markedly, and there is nearly no emulsion phase left in the colorimetrical cylinder after the concentration of $\mathrm{NaCl}$ exceeds $12 \mathrm{~g} / \mathrm{L}$. When the salinity increases, inorganic salt ion will produce salting-out effect on anionic surfactant, and the effect can make the adsorption of surfactant molecules on the interface become unconsolidated. Then some surfactant molecules go into the oil phase, and the strength of interfacial film decreases. As a result, the emulsion stability gets weak due to the rising inorganic salt. Compared with ABS, the emulsion stability of APG is quite excellent, since it almost does not change with the variation of salinity. As 


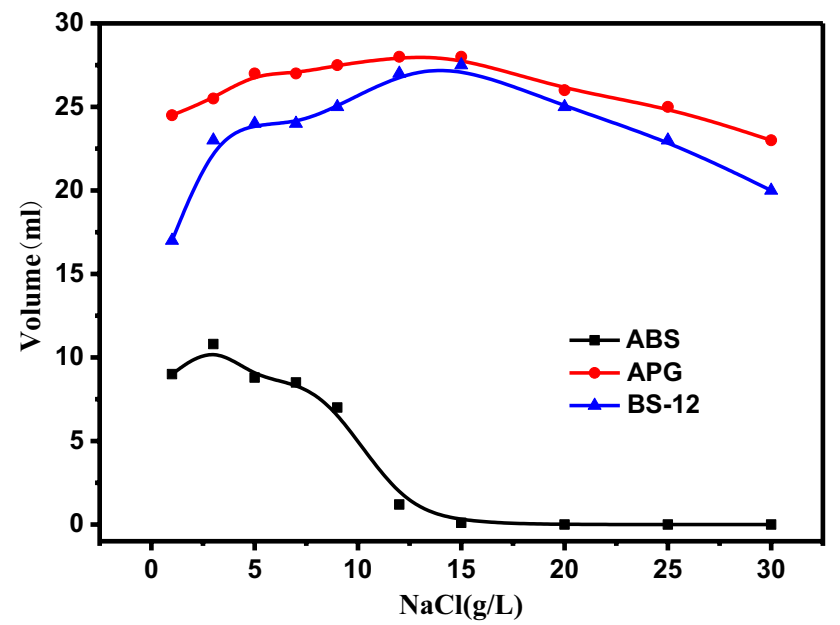

Fig. 13 Effect of $\mathrm{NaCl}$ on the volume of emulsion phase at 5th min

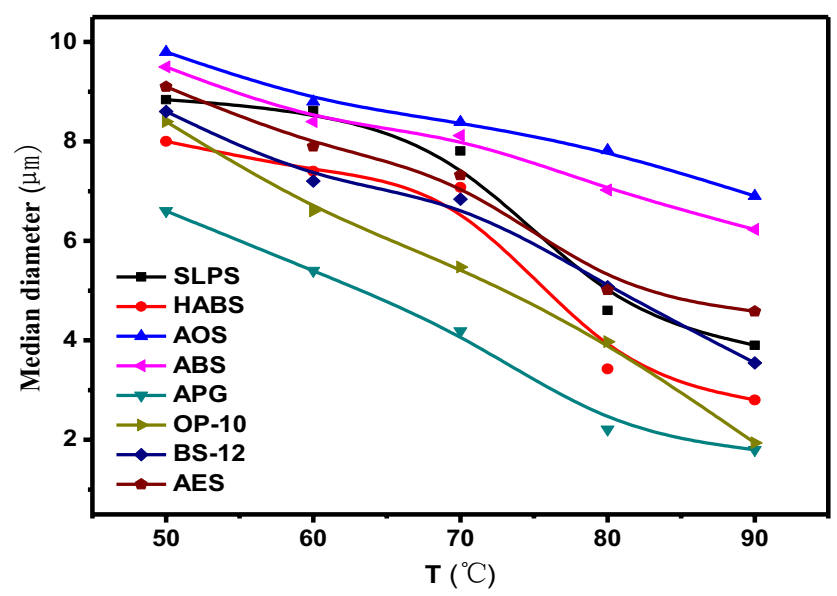

Fig. 14 Median diameter of emulsified oil droplet at different temperature

a nonionic surfactant, there is nearly no salting-out effect on APG. In addition, inorganic salt can compress the polar head of APG molecule. Then the arrangement of APG molecule at the oil-water interface gets closer, and the maximum adsorption increases (Han et al. 2009). Therefore, the emulsion stability of APG which can produce the stabilized interfacial film is much better.

\section{Emulsified oil droplet size}

Emulsified oil droplet size is the fundamental indicator to assess the ability of emulsion to get through the pore throat of the reservoir. Small emulsified oil droplet has more excellent fluidity in the pore throat, and it is beneficial to improve the sweep efficiency. The median diameter of emulsified oil droplet at different temperature is shown in Fig. 14. It is very clear that the median diameter decreases along with the increase in the temperature. The reason may be that increasing temperature improves the solubilization ability of micelles for oil droplet (Zhang et al. 2008). In addition, the emulsified oil droplet formed by APG is smaller than that produced by others. It may be related to the quantity and structure of the micelles in the solution. Since the CMC of APG is the lowest among those of all surfactants, the number of micelles is the most when the concentration of surfactant is the same. Besides, due to the cyclic molecule structure, APG produces the loose micellar structure which can solubilize more oil molecules. Micro-morphology of emulsion prepared with APG at different temperature is shown in Fig. 15, and it has verified the relation between emulsified oil droplet size and temperature, that is, high temperature is favorable to form small emulsified oil droplets.

\section{Correlations between the activity and emulsification properties of APG}

\section{Correlation between IFT and emulsifying ability}

The correlation between IFT and emulsifying ability of APG is shown in Fig. 16. It is very clear that there is a closed relationship between IFT and emulsifying ability, that is, the emulsifying ability has negative correlation with IFT. The emulsifying ability reduces along with the increase in the IFT. However, the correlation between IFT and emulsifying ability is not a corresponding relationship, that is, surfactants having the same emulsifying ability may attain different IFTs with oil. In brief, surfactants with different interfacial activity can possess identical emulsifying ability. The different molecule structures of surfactants may be the basic reason why the result above is obtained (Chen et al. 2012).

\section{Correlation between IFT and emulsion stability}

The correlation between IFT and emulsion stability of APG is reflected in Table 3. For one surfactant, IFT is negatively related to emulsion stability, that is, reducing IFT can improve the emulsion stability. The reason may be as follows: increasing the number of surfactant molecule at the oil-water interface which can decrease the IFT enhances the binding force between the oil and water, and then the stability of interfacial film is improved. As a result, the emulsion stability gets better. Nevertheless, it does not mean that the lower the IFT is, the more stable the emulsion will be. Some researchers have proved that too low IFT results in the decrease in emulsion stability (Kang et al. 2005). Hence, to keep the emulsion from demulsifying, the properly low IFT is necessary. 


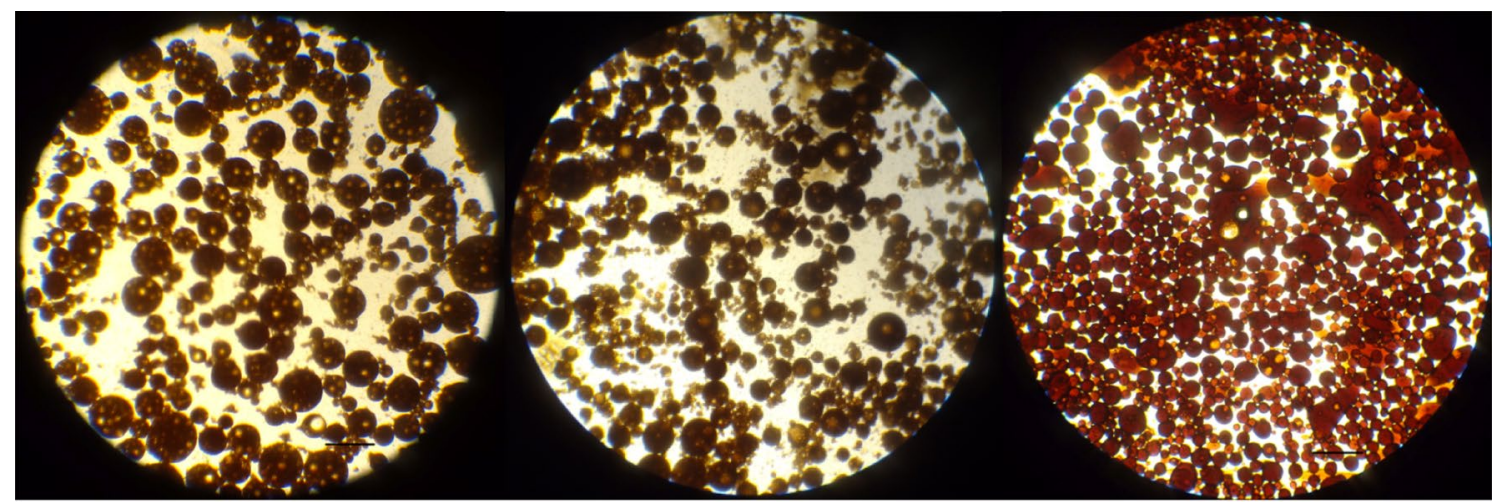

$50^{\circ} \mathrm{C}$

$60^{\circ} \mathrm{C}$

$70^{\circ} \mathrm{C}$

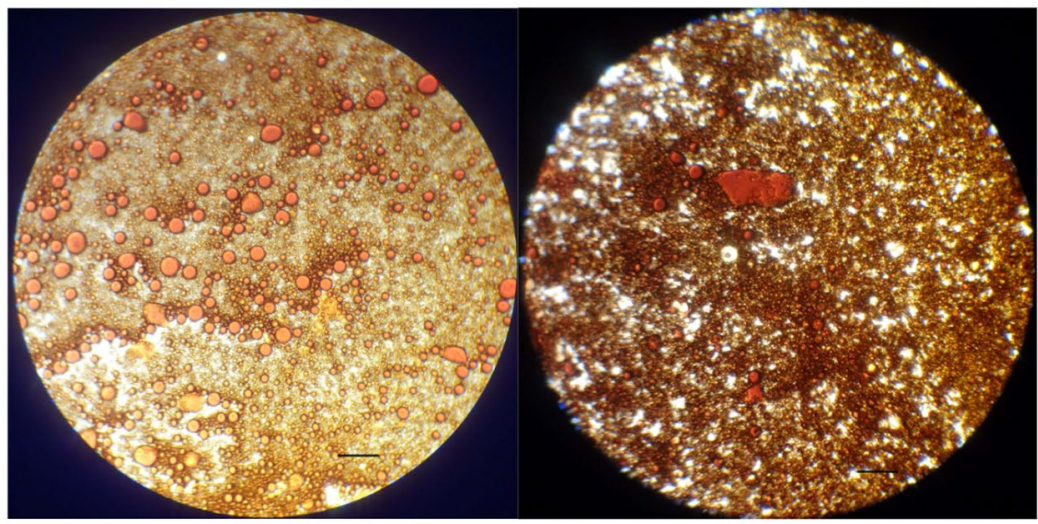

$80^{\circ} \mathrm{C}$

$90^{\circ} \mathrm{C}$

Fig. 15 Micro-morphology of emulsion prepared with APG at different temperature

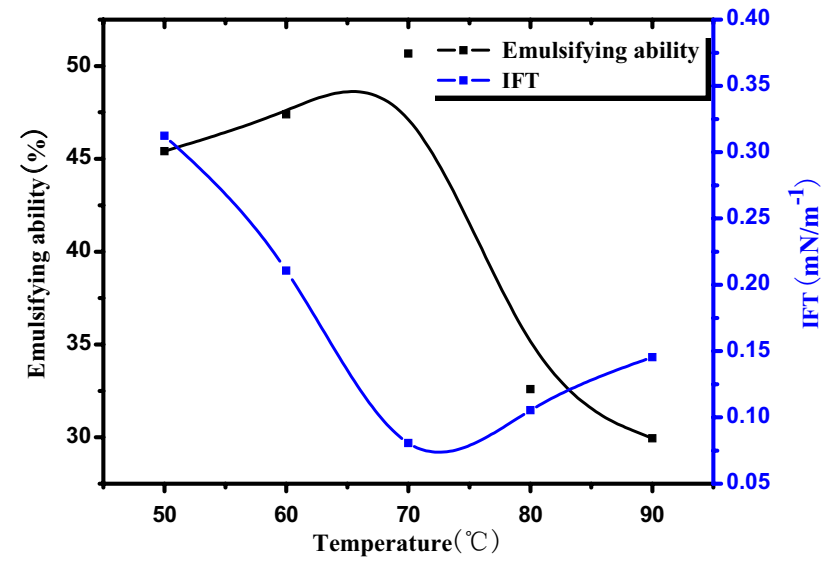

Fig. 16 Relation between emulsifying ability and IFT of APG

\section{Performance of APG flooding in sandpacks}

In order to compare the effectiveness of different surfactant floodings for heavy oil, a series of sandpack flooding tests (Run A to Run F) were conducted. APG,
Table 3 IFT and emulsion phase volume of APG1214

\begin{tabular}{|c|c|c|c|c|c|}
\hline $\mathrm{V}, \mathrm{ml} \quad \mathrm{C}, \%$ & 0.1 & 0.2 & 0.3 & 0.4 & 0.5 \\
\hline 3 & 21 & 23 & 25 & 26 & 29 \\
\hline 5 & 18 & 17 & 20 & 27 & 28 \\
\hline 10 & 16 & 17 & 19 & 25 & 27.5 \\
\hline 30 & 16 & 16 & 18 & 20 & 27 \\
\hline 60 & 15 & 15 & 16 & 17 & 25 \\
\hline 120 & 15 & 15 & 16 & 16.5 & 18 \\
\hline $\mathrm{IFT}, \mathrm{mN} / \mathrm{m}$ & 0.380 & 0.323 & 0.156 & 0.152 & 0.150 \\
\hline
\end{tabular}

BS-12 and ABS were selected for tertiary oil recovery core flood tests. The result is shown in Table 4. The incremental recovery rises as the concentration of APG increases, and it can reach to $10.1 \%$ which is nearly two times higher than that of BS-12 and ABS when the surfactant concentration is the same. Thus, APG flooding demonstrates the enormous potential to enhance heavy oil recovery remarkably at high-temperature and highsalinity reservoir. 
Table 4 Summary of sandpack flooding tests

\begin{tabular}{lllllll}
\hline Test & $\begin{array}{l}\text { Permeability } \\
(\mathrm{mD})\end{array}$ & $\begin{array}{l}\text { Initial oil satu- } \\
\text { ration (\%) }\end{array}$ & Chemical formula & \multicolumn{2}{l}{ Oil recovery(\%) } & \\
\cline { 5 - 7 } & & & Water flooding & $\begin{array}{l}\text { Chemical } \\
\text { flooding }\end{array}$ & Total \\
\hline $\mathrm{A}$ & 1317 & 89.6 & $0.3 \% \mathrm{ABS}$ & 27.3 & 3.2 & 30.5 \\
$\mathrm{~B}$ & 1342 & 88.3 & $0.3 \% \mathrm{BS}-12$ & 28.9 & 5.4 & 34.3 \\
$\mathrm{C}$ & 1268 & 89.2 & $0.1 \% \mathrm{APG}$ & 27.1 & 3.6 & 30.7 \\
$\mathrm{D}$ & 1302 & 89.1 & $0.2 \% \mathrm{APG}$ & 26.4 & 7.8 & 34.2 \\
$\mathrm{E}$ & 1382 & 88.6 & $0.3 \% \mathrm{APG}$ & 27.1 & 10.1 & 37.2 \\
$\mathrm{~F}$ & 1219 & 88.9 & $0.4 \% \mathrm{APG}$ & 25.0 & 11.4 & 36.4 \\
\hline
\end{tabular}

\section{Conclusions}

By analyzing the surface tension, interfacial tension, emulsifying ability, emulsion stability and emulsified oil droplet size for the eight surfactants, it is found that APG has excellent interfacial activity and emulsification properties. Besides, the interfacial activity and emulsification properties of APG are nearly not influenced by the temperature and $\mathrm{NaCl}$ due to the special molecular structure, while those of other surfactants are affected in different degrees. The incremental recovery can reach to $10.1 \%$ which is nearly two times higher than that of common surfactant when the surfactant concentration is the same. Thus, it can be concluded that APG can be used successfully as the displacement agent for the common heavy oil at hightemperature and high-salinity reservoir condition.

Acknowledgements Financial support by National Natural Science Foundation of China (51704035) is gratefully acknowledged.

Open Access This article is distributed under the terms of the Creative Commons Attribution 4.0 International License (http://creativeco mmons.org/licenses/by/4.0/), which permits unrestricted use, distribution, and reproduction in any medium, provided you give appropriate credit to the original author(s) and the source, provide a link to the Creative Commons license, and indicate if changes were made.

\section{References}

Balzer D (1991) Alkylpolyglcosides, their physico-chemical properties and their uses. Tenside Surfactants Deterg 38:419-427

Bi Z, Zhang Z, Xu F, Qian Y, Yu J (1999) Wettability, oil recovery, and interfacial tension with an SDBS-dodecane-kaolin system. J Colloid Interface Sci 214:368-372

Chen L, Zhao X, Wang Z, Bai Y (2012) Effect of molecular structure on interfacial activity and emulsification property. Tenside Surfactants Deterg 49:394-397

Chen L, Zhang G, Ge J et al (2013a) Research of the heavy oil displacement mechanism by using alkaline/surfactant flooding system. Colloids Surf A 434:63-71

Chen L, Zhao X, Wang Z, Tang J, Feng B, Tang M (2013b) Research on the emulsifying ability of surfactants for crude oil. Tenside Surfactants Deterg 50:434-440
Chiang M, Shah SO (1979) A correlation of interfacial tension with oil displacement efficiency for equilibrated and non-equilibrated oil/brine/surfactant systems. SPE8724-PA

Ding B, Zhang G, Ge J, Liu X (2010) Research on mechanisms of alkaline flooding for heavy oil. Energy Fuels 24:6346-6352

Gafonova OV, Yarranton HW (2001) The stabilization of water-inhydrocarbon emulsions by asphaltenes and resins. J Colloid Interface Sci 241:469-478

Guo C (2010) Research of interfacial tension and emulsification performance relevance of ASP compound system. Petrochem Ind Appl 29:20-22

Han M, Ji G, Ni J (2009) Mechanism for enhanced oil removal by inorganic salts during washing crude oil contaminated soil with alkyl polyglucoside. Acta Phys Chim Sin 25:2026-2033

Iglauer S, Wu YF, Shuler P, Tang YC, Goddard WA (2009) Alkyl polyglucoside surfactant-alcohol cosolvent formulations for improved oil recovery. Colloids Surf A 339:48-59

James EV (1980) Correlation of emulsion stability with phase behavior in surfactant systems for tertiary oil recovery. SPE6675-PA

Jiang T, Hirasaki G, Miller C, Moran K (2008) Using silicate and pH control for removal of the rag layer containing clay solids formed during demulsification. Energy Fuels 22:4158-4164

Kahlweit M, Busse G, Faulhaber B (1995) Preparing microemulsions with alkyl monoglucosides and the role of n-alkanols. Langmuir 11:3382-3387

Kang W, Li J, Zhao X (2005) Effect of interfacial tension and emulsified oil droplet size on the stability of emulsion. Oil Gas Fields Surf Proj 24:11-12

Kutschmann EM, Findenegg GH, Nickel D, Rybinski W (1995) Interfacial tension of alkylpolyglucosides in different APG/oil/water systems. J Colloid Polym Sci 273:565-571

McClean JD, Kilpatrick PK (1997) Effects of asphaltene aggregation in model heptane-toluene mixtures on stability of water-in-oil emulsions. J Colloid Interface Sci 196:23-34

Monika S, Gabriela A, Stefan B, Paul B, Christian S, Gregor B (2011) Sustainable surfactants in enhanced oil recovery. In: SPE enhanced oil recovery conference held in Kuala Lumpur, Malaysia, 19-21 July 2011

Norman RM (1990) Wettability and its effect on oil recovery. SPE21621-PA

Payet L, Terentjev EM (2008) Emulsification and stabilization mechanisms of $\mathrm{O} / \mathrm{W}$ emulsions in the presence of chitosan. Langmuir 24:12247-12252

Salager JL, Morgan JC, Schechter RS, Wade WH, Vasquez E (1979) Optimum formulation of surfactant/water/oil systems for minimum interfacial tension or phase behavior. SPE 7054-PA

Sun L, Pu W, Wu Y, Xin J (2011) Study on the emulsification property of surfactant in high-temperature condition. Oilfield Chem 28:275-279 
Taylor KC, Schramm LL (1990) Measurement of short-term low dynamic interfacial tensions: application to surfactant enhanced alkaline flooding in enhanced oil recovery. Colloids Surf 47:245-253

Wasan DT, Shah SM, Aderangi N (1978) Observations on the coalescence behavior of oil droplets and emulsion stability in enhanced oil recovery. SPE6846-PA
Zhang H, Xu G, Wu D (2008) Aggregation of cetyltrimethylammonium bromide with hydrolyzed polyacrylamide at the paraffin oil/water interface: interfacial theological behavior study. Colloids Surf A 317:289-296

Publisher's Note Springer Nature remains neutral with regard to jurisdictional claims in published maps and institutional affiliations. 